\title{
Mechanical and Structural Properties of High Purity Al Processed by ECAP
}

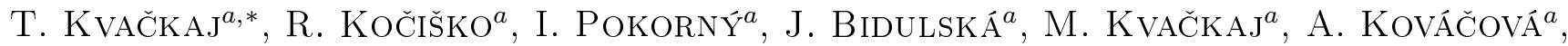 \\ R. BidulskÝ ${ }^{b}$, L. LityŃSKA-DOBRZYŃSKA ${ }^{c}$ AND J. DUtKIEWICZ ${ }^{c}$ \\ ${ }^{a}$ Department of Metals Forming, Faculty of Metallurgy, Technical University of Košice \\ Letná 9, 04200 Košice, Slovakia \\ ${ }^{b}$ Politecnico di Torino, Sede di Alessandria, 15 100, T. Michel, 5, Alessandria, Italy \\ ${ }^{c}$ Institute of Metallurgy and Materials Science, Polish Academy of Sciences \\ W.S. Reymonta 25, 30-059 Kraków, Poland
}

\begin{abstract}
The mechanical properties and substructure formation of high purity aluminium (99.999\%) processed by severe plastic deformation method (equal channel angular pressing) were studied. The equal channel angular pressing process was carried out at room temperature by route $\mathrm{C}$ (sample rotation around the axis about $180^{\circ}$ after each pass) in a die with two channels intersecting at an angle of $\Phi=90$. The softening mechanism through dynamic recovery was recognized up to 6th equal channel angular pressing pass, however, after that the mechanical strengthening was revealed. The samples after equal channel angular pressing processing were annealed in different temperature and time conditions. The influence of annealing temperature and time on microhardness as well as diameter of grain size were investigated in samples processed by the 4th equal channel angular pressing pass.
\end{abstract}

PACS: 81.05.Bx, 81.07.-b, 81.20.Hy, 81.40.-z

\section{Introduction}

Demands of industrial producers are to find new forms and facilities for appropriate properties of structural parts suitable for different miscellaneous constructive applications in the civil, automotive and aircraft industries. Considering these facts, aluminium alloys provide various possibilities because of their remarkable combination of characteristics such as low density, high corrosion resistance, high strength, easy workability, and high electrical and heat conductivity.

Conventional forming methods are ineffective in achieving of favourable properties of produced parts because ultrafine grained (UFG) structure is not formed. Moreover, only limited levels of structural and strength-plastic characteristics can be obtained through conventional forming methods. An application of non-conventional forming methods $[1,2]$ as well as severe plastic deformation (SPD), such as the most preferred methods of equal channel angular pressing (ECAP) and equal channel angular rolling (ECAR) technologies [3, 4] could be the solution. They provide the possibility to obtain the UFG structure at the nm level. Ultrafine-grained polycrystalline metals prepared by SPD methods offer a suitable combination of strength and ductility. It is

* corresponding author; e-mail: tibor.kvackaj@tuke.sk unique and it indeed represents interesting cases from the point of view of mechanical properties [5-8]. In recent years, the scientific research has been focused on the increase of strength in $\mathrm{Al}$ alloys by SPD methods without any ageing treatment [9].

The observation of the material structure through transmission electron microscopy (TEM) is useful and it is used to confirm the various theories about material behaviour during the ECAP processing $[10,11]$.

The given paper is focused on the study of the SPD influence on the properties and structural changes in high purity aluminium (99.999\%) processed by 12 ECAP passes at room temperature.

\section{Experimental procedures}

As an experimental material, the high purity aluminium (99.999\%) after zonal refining was used. The structure of as-received $\mathrm{Al}$ was heterogeneous with average grain size $d_{\mathrm{g}} \approx 650 \mu \mathrm{m}$. The mechanical properties before ECAP processing are given in Table.

TABLE I

Initial mechanical properties of high purity aluminium (99.999\%).

\begin{tabular}{c|c|c|c}
\hline \hline $0.2 \%$ YS [MPa] & UTS [MPa] & El. [\%] & HV10 [-] \\
\hline 36 & 52 & 27 & 24.2
\end{tabular}


The ECAP process was carried out at room temperature by route $\mathrm{C}$ (sample rotation around the axis about $180^{\circ}$ after each pass). The ECAP die contains two channels intersecting at an angle of $\Phi=90^{\circ}$. The samples with a cylindrical cross-section $\left(d_{0}=10 \mathrm{~mm}\right.$, $l_{0}=80 \mathrm{~mm}$ ) were extruded by 12 ECAP passes at the rate of $1 \mathrm{~mm} \mathrm{~s}^{-1}$. The deformation forces during ECAP processing were measured using a tensometric measuring device with LabVIEW apparatus. Moreover, static tensile using samples with parameters $d_{0} \times l_{0}=5 \times 10 \mathrm{~mm}^{2}$ was performed. The samples designated for tensile tests were taken from every second ECAP pass. Tensile tests were carried out using ZWICK 1387 equipment in standard conditions (EN 10002-1). Subsequently, the mechanical properties such as yield strength (YS), ultimate tensile strength (UTS) and elongation to failure (El.) were determined. TEM analysis with selected area diffraction patterns (SADP) was performed using Philips CM 20 microscope. Thin foils taken from the longitudinal direction were prepared using a solution of $5 \% \mathrm{HF}$ at a temperature of $-25^{\circ} \mathrm{C}$ and the time $20-30 \mathrm{~s}$. The results were processed by mathematical numerical methods and a software product MATLAB.

\section{Results and discussion}

The change of mechanical properties in dependence on the ECAP number passes is shown in Fig. 1. As is seen, UTS is slightly sensitive to ECAP passes and substructure formation. The yield strength $(0.2 \%$ offset $)$ is decreasing up to the 6 th pass where it achieved local minimum. From the 6th up to 12 th pass, YS is growing. The progress of elongation to failure (El.) is inverse to the progress of $0.2 \% \mathrm{YS}$.

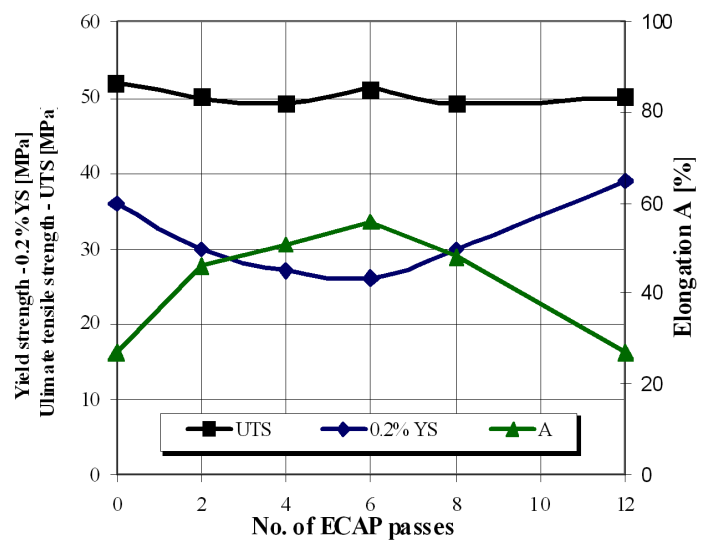

Fig. 1. Development of mechanical properties vs. ECAP number passes.

TEM analysis was performed using samples after the 4th, 6th, 8th and 12th ECAP passes. Initial structure included large polyedric grains $\left(d_{\mathrm{g}} \approx 650 \mu \mathrm{m}\right)$ and low dislocation density. The cell substructure with subgrain diameter $d_{\text {sg }} \approx 2.6 \mu \mathrm{m}$ was observed after the 4 th and 6 th ECAP passes. The dislocations are generated gradually with the increase of strain and subsequently arranged to dislocation walls which later transform to low or high angles grain boundaries. Subgrains are equiaxed with the average size of $d_{\mathrm{sg}} \approx 2.2 \mu \mathrm{m}$. After the $12 \mathrm{th}$ ECAP pass, the substructure was equiaxed with a low misorientation and the average subgrain size of $d_{\mathrm{sg}} \approx 1 \mu \mathrm{m}$. The average subgrain size in dependence on ECAP number passes is given in Fig. 2 .

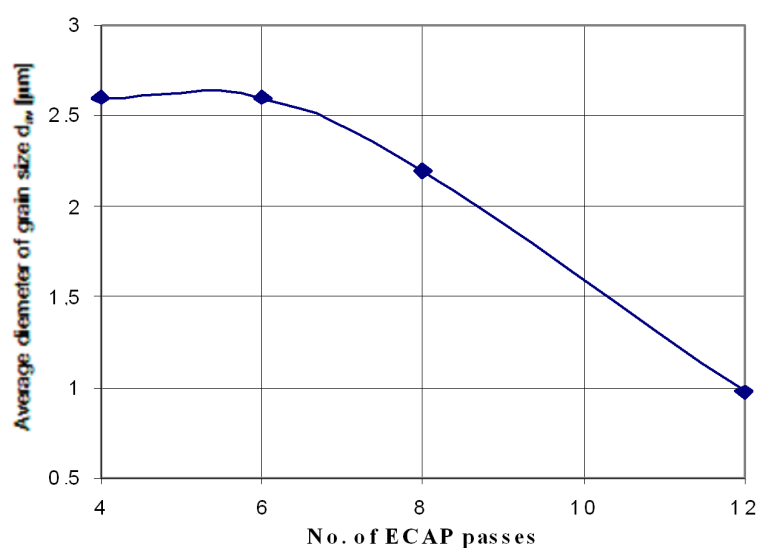

Fig. 2. The grain size dependence on ECAP passes.

The significant substructure refinement was observed after the 6th ECAP pass. Moreover, after the 6th pass, the yield strength starts to grow which corresponds to the Hall-Petch equation which describes the material strengthening in dependence on the grain size refinement. Random coarse grains included in fine structure matrix were observed after the 4 th and 12th ECAP pass as shown in Fig. 3.
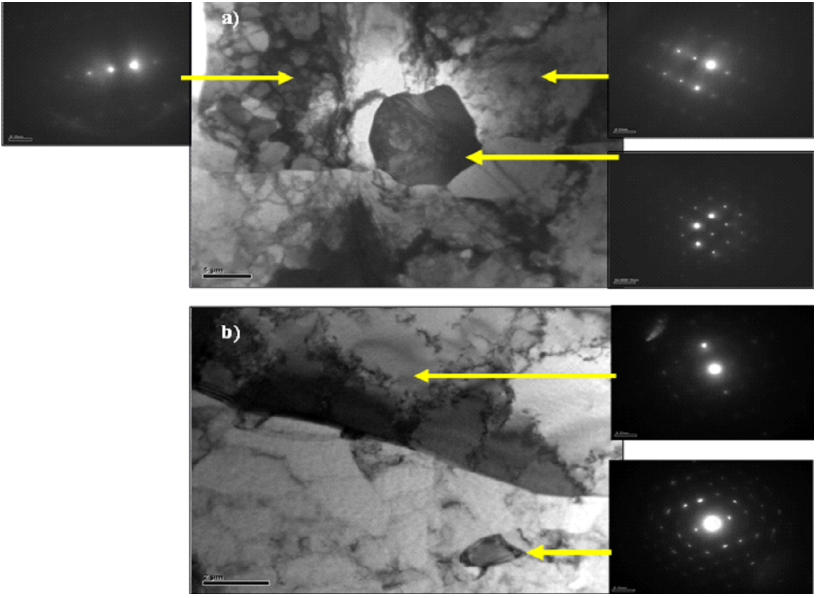

Fig. 3. Recrystallized grains after ECAP processing: (a) the 4th ECAP pass; (b) the 12th ECAP pass.

This anomaly is caused by local occurrence of recrystallized grains in a structure which has high angle grain boundaries (HAGB). The recrystallization in high purity aluminium (99.999\%) which was deformed at the room 
temperature is described in the [12] as a dynamic/static recrystallization (DRX, SRX). The less pure aluminium recrystallized more slowly than the purer one $[13,14]$. According to the literature, the sensitivity to softening in aluminium (dynamic or static mechanism) depends on the purity of aluminium strongly.

The measurement of the deformation forces during ECAP processing was performed using two different materials (high purity aluminium and oxygen free high conductivity (OFHC) $\mathrm{Cu}$ ). The measurement was carried out by tensometric sensors and subsequently forces were recalculated to the values of stresses, illustrated in Fig. 4.

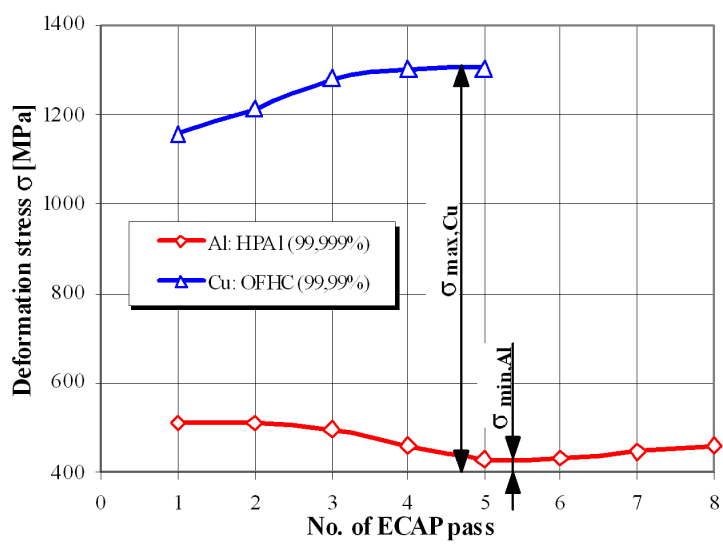

Fig. 4. Dependence of deformation stresses on ECAP passes for different materials.

For the aluminium material, there was observed the decrease of deformation stress, on the other hand in copper the increase was observed. The different progress of deformation stresses is likely connected with the stacking fault energy (SFE). The high purity aluminium is a material with high SFE $\left(166 \mathrm{~mJ} \mathrm{~m}^{-2}\right)$ while OFHC copper has low SFE (40 mJ m $\left.{ }^{-2}\right)[15,16]$. Materials with high SFE are characterised by the dynamic recovery while materials with low SFE by the deformation strengthening that is followed by some kind of recrystallization mechanisms, which has a good correlation with observed graphical experimental data. Therefore, the decrease of deformation stress in high purity aluminium was observed up to the 6th ECAP pass which is caused by the dynamic recovery though on the other hand, from the 6th ECAP pass, deformation stress was slightly growing.

The development of the elongation is inverse to the yield strength with emerging inflexed point in the 6th ECAP pass (Fig. 1). These dependences are related to the mechanical strengthening mechanism resulting from the refinement of grain size (Fig. 2). As is seen in Fig. 4, deformation stress for both materials $\left(\sigma_{\max , \mathrm{Cu}} / \sigma_{\min , \mathrm{Al}}\right)$ was 0.33 in the 5 th ECAP pass. It means that softening mechanisms of $\mathrm{Al}$ carried out through a dynamic recovery needs only $33 \%$ from the maximal level of mechanical strengthening of $\mathrm{OHFC} \mathrm{Cu}$. The influence of the annealing temperature and time on the microhardness and diameter of grain size in samples processed by four
ECAP passes was observed. Experimental data were processed by nonlinear statistical methods. Two regression equations were derived to describe the relations between $\mathrm{HV}=f\left(T_{A}, t_{A}\right)$ and $d_{\mathrm{sg}}=f\left(T_{A}, t_{A}\right)$ as a function of the annealing temperature and time:

1) relation $\mathrm{HV}=f\left(T_{A}, t_{A}\right)$

The equation describing the relationship between microhardness and annealing temperature, time is described by the following nonlinear regression model:

$\mathrm{HV}=a_{1}\left(T_{A}\right)+a_{2}\left(T_{A}\right)\left[1-\exp \left(-a_{3}\left(T_{A}\right) t_{A}\right)\right]$,

where $t_{A}[\mathrm{~min}]$ - annealing time, $T_{A}\left[{ }^{\circ} \mathrm{C}\right]$ - annealing temperature, and $a_{i}\left(T_{A}\right)$ - regression coefficients functionally dependent on the $T_{A}(i=1,2,3)$ [17].

2) relation $d_{\mathrm{g}}=f\left(T_{A}, t_{A}\right)$

The relationship between the diameter of grain size and the annealing temperature and time is described by the following nonlinear regression model:

$$
d_{\mathrm{g}}=b_{1}\left(T_{A}\right)+b_{2}\left(T_{A}\right)\left[1-\exp \left(-b_{3}\left(T_{A}\right) t_{A}\right)\right],
$$

where $b_{i}\left(T_{A}\right)$ - regression coefficients functionally dependent on the $T_{A}(i=1,2,3)[17]$.

Graphical interpretations of regression Eqs. (3.1, 3.2) are given in Figs. 5 and 6.

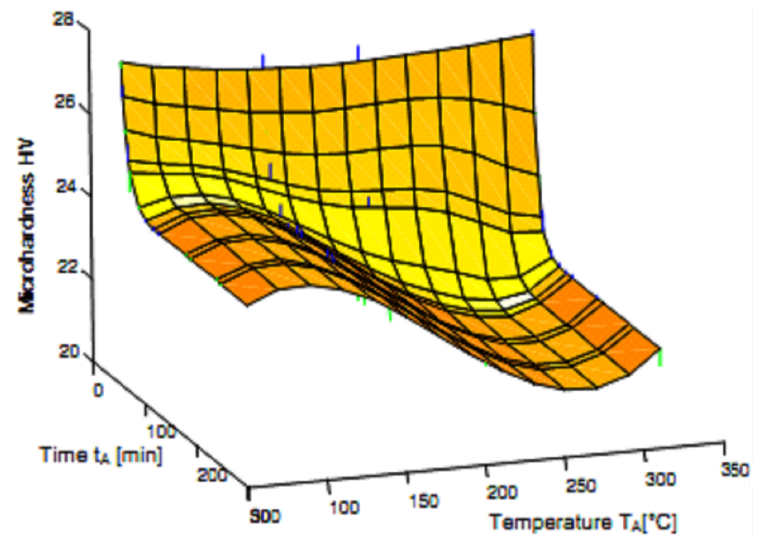

Fig. 5. The dependence of microhardness on annealing temperature and time.

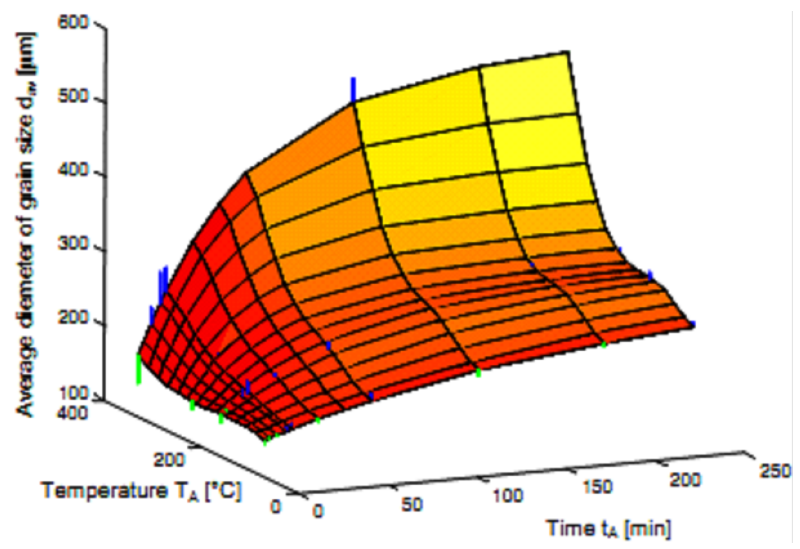

Fig. 6. The dependence of grain size diameter on annealing temperature and time. 
The deviations from experimental values are shown as line segments on the calculated surface. The correlation between experimental and calculated data is good. According to the diagrams:

- the microhardness decreases significantly up to the annealing time $t_{A} \approx 30 \mathrm{~min}$, after that steady state was reached,

- in the steady state, the microhardness depending on annealing time shows two groups of values:

- the 1st group - HV $\approx 23.5$ for $T_{A}=70$ and $160^{\circ} \mathrm{C}$,

- the 2nd group - HV $\approx 21.5$ for $T_{A}=220$ and $330^{\circ} \mathrm{C}$.

The difference between both groups is caused by the structural softening from a thermally activated process.

- grain size diameter is increasing rapidly at the annealing temperature $T_{A}>220^{\circ} \mathrm{C}$.

\section{Conclusion}

The investigation of high purity Al (99.999\%) processed by the ECAP method revealed a negligible impact of number passes on the ultimate tensile strength. The ultimate tensile strength was changed only in the interval of UTS $=49-52 \mathrm{MPa}$. However, the influence of number passes on yield strength, elongation, microhardness and subgrain diameter was more obvious. The values were changed in the following intervals: YS $=26-39 \mathrm{MPa}$, $A=27-56 \%, d_{\mathrm{g}}=650-1 \mu \mathrm{m}$. High purity $\mathrm{Al}$ is a material with high stacking fault energy, therefore a softening mechanism through the dynamic recovery was observed up to the 6th ECAP pass. On the other hand, from the 6th ECAP pass, the mechanical strengthening was seen. The good correlation between mechanical and substructural properties was obtained. The stress ratio for both materials $\left(\sigma_{\max , \mathrm{Cu}} / \sigma_{\min , \mathrm{Al}}\right)$ resulting from graphical dependences was 0.33 , which means that softening mechanisms through dynamic recovery of $\mathrm{Al}$ needed only $33 \%$ from the maximal level of the overall OHFC $\mathrm{Cu}$ mechanical strengthening. Two regression models derived from experimental results describing the influence of annealing conditions on the microhardness $\mathrm{HV}=f\left(T_{A}, t_{A}\right)$ and the grain size diameter $d_{\mathrm{g}}=f\left(T_{A}, t_{A}\right)$ were determined. The microhardness decreased significantly when the annealing time was $t_{A} \approx 30 \mathrm{~min}$, after that the steady state was reached. The grain size diameter increased rapidly when the annealing temperature was $T_{A}>220^{\circ} \mathrm{C}$.

\section{Acknowledgments}

This work was supported by the Slovak national agency VEGA $1 / 0359 / 11$, VEGA $1 / 0385 / 11$ and the bilateral project SK-PL-0011-09 of agency APVV.

\section{References}

[1] T. Kvačkaj, L. Sokolová, M. Vlado, V. Vrchovinský, R. Mišičko, Z. Nový, High Temp. Mater. Process. 23, 1 (2004).

[2] T. Kvačkaj, L. Sokolová, M. Vlado, V. Vrchovinský, High Temp. Mater. Process. 24, 139 (2005).

[3] T. Kvačkaj, M. Kvačkaj, V. Stoyka, R. Kočiško, J. Bidulská, J. Bacsó, Mater. Sci. Forum 667-669, 133 (2011).

[4] M. Kvačkaj, T. Kvačkaj, A. Kováčová, R. Kočiško, J. Bacsó, Acta Metall. Slovaca 16, 84 (2010).

[5] R.Z. Valiev, I.V. Alexandrov, Y.T Zhu, T.C. Lowe, J. Mater. Res. 17, 5 (2002).

[6] B.Q. Han, E.J. Lavernia, F.A. Mohamed, Rev. Adv. Mater. Sci. 9, 1 (2005).

[7] I.A. Ovidko, Rev. Adv. Mater. Sci. 10, 89 (2005).

[8] M.A. Meyers, A. Mishra, D.J. Benson, Prog. Mater. Sci. 51, 427 (2006).

[9] T. Kvačkaj, J. Bidulská, M. Fujda, R. Kočiško, I. Pokorný, O. Milkovič, Mater. Sci. Forum 633-634, 273 (2010).

[10] J. Dutkiewicz, F. Masdeu, P. Malczewski, A. Kukuła, Arch. Mater. Sci. Eng. 39, 80 (2009).

[11] I.V. Alexandrov, M.V. Zhilina, A.V Scherbakov, A.I. Korshunov, P.N. Nizovtsev, A.A. Smolyakov, V.P. Solovyev, I.J. Beyerlein, R.Z. Valiev, Arch. Metall. Mater. 50, 281 (2005).

[12] C. Choi, J. Jeong, C. Oh, D.N. Lee, Scr. Metall. Mater. 30, 325 (1994).

[13] W.J. Kim, C.S. Chung, D.S. Ma, S.I. Hong, H.K. Kim, Scr. Mater. 49, 333 (2003).

[14] W.J. Kim, J.Y. Wang, Mater. Sci. Eng. A 464, 23 (2007).

[15] F.J. Humphreys, M. Hartherly, Recrystallization and Related Annealing Phenomena, Pergamon Press, Oxford, U.K. 1995.

[16] K. Neishi, Z. Horita, T.G. Langdon, Mater. Sci. Eng. A 325, 54 (2002).

[17] T. Kvačkaj, J. Bidulská, R. Kočiško, R. Bidulský, in: Aluminium Alloys (Theory and Applications), Eds. T. Kvačkaj, R. Bidulský, Intech, Rijeka 2011, p. 3. 